\title{
Using gestures and English as a Foreign Language vocabulary learning: Does gender make a difference?
}

\author{
Ghasemi, Ehsan $\gg$ \\ Texas Tech University, USA (Ehsan.ghasemi@ttu.edu) \\ Feyzi Behnagh, Reza \\ University at Albany, USA (rfeyzibehnagh@albany.edu)
}

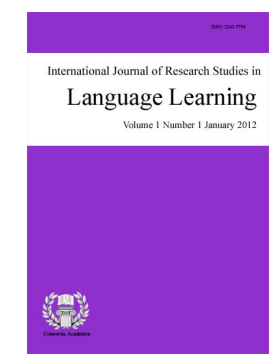

ISSN: $2243-7754$

Online ISSN: 2243-7762

Received: 22 March 2017

Revised: 17 May 2017

DOI: $10.5861 /$ ijrsll.2017.1784

Accepted: 1 June 2017

OPEN ACCESS

\section{Abstract}

This study aimed at investigating possible gender differences of adult EFL learners in terms of the effects of semantic elaboration (operationalized through teacher-performed gestures) on memory for new words in English and words in native tongue. To achieve this goal, thirty male and thirty female university students were randomly selected and each of the groups went through the experiment separately. They were presented with two sets of new English words (determined through a pretest) and were instructed to do their best to learn the words in two conditions. One set consisted of word-translation pairs (control condition) and the other set consisted of word-translation pairs followed by a video showing the meaning of each word through gestures. Each participant was presented with every experimental word but in two different orders. Then they were required to complete two recall tasks (i.e. free recall in English, free recall in Persian). The results of data analysis using repeated measures of ANOVA (two-way and one-way) showed a negative effect of using gestures on free recall in English and a positive effect of using gestures on free recall in Persian for both groups. Based on the results some pedagogical implications are provided.

Keywords: semantic elaboration; English as a foreign language; free recall; gestures; word learning; gender 


\section{Using gestures and English as a Foreign Language vocabulary learning: Does gender make a difference?}

\section{Introduction}

There are numerous studies investigating different aspects of L2 vocabulary learning, such as studies dealing with active/passive vocabulary repertoire (e.g., Crow \& Quigly, 1985; Laufer \& Paribakht, 1988), the order of learning the vocabulary of a language (Dulay \& Burt, 1974; Goldschneider \& DeKeyser, 2001), corpus analyses for designing high-frequency word lists (e.g., Meara, 1995; Schmitt, 2000; West, 1953), efficient ways of teaching vocabulary (e.g,, Folse, 2006; Fraser,1999), and vocabulary learning strategies including direct and incidental methods of vocabulary learning (Batia \& Jan, 2001; Brown \& Perry, 1991). One related field that has relatively been explored less is the processing of input at the level of words in the foreign language. Based on information processing theories, in order to learn a new word, both its meaning and form should be attended and processed. Word processing normally includes three stages. In the first stage, learners pay attention to the structure of the word (form) and encode it in their mind (for example the length of the word, number of letters and syllables, and its visual and acoustic characteristics). Then, semantic structures related to the meaning of the new word is activated or built in the learners' minds. L1 and L2 words seem to be different in this respect: for L2 words these structures are in mind and only need to be activated but for L1 words, they may need to be built (Ausubel, 1964; Jiang, 2002; Levelt, 1989); the same is the case for known and unknown words (Giacobbe, 1992; Ringbom, 1983). And finally, in the stage of mapping, the encoded item is matched with proper meaning.

Since it is not possible to teach students all L2 words, a logical substitute is identifying and teaching effective vocabulary learning strategies (Oxford, 1986). One of the vocabulary learning strategies which started to receive attention by researchers in the late 1980s and early 1990s is semantic elaboration (sometimes referred to as deep semantic processing). Semantic elaboration is a term which implies focusing more on semantic aspects of the new word and allocation of available resources mainly to its meaning during learning.

\subsection{Statement of the Problem}

Previous studies show positive effects of semantic elaboration on memory for L1 known words and memory for other types of stimuli including sentence recall and text recall (Barcroft, 2004). However, in regards to new words (especially in FL learning) that effect is not necessarily positive. Sometimes, the resources that are used to focus on semantic features of the new word in FL learning can be allotted to the structural features and matching the form and the meaning of the new word.

In reviewing the related literature, the authors could not find studies dealing with possible gender difference in the role of semantic elaboration on foreign or second language word learning; therefore the main focus of the present study is investigation of the role of gender in this relationship. In EFL classes when instructors want to introduce a new word they usually utilize semantic elaboration techniques such as using pictures, synonyms, asking questions about the word, referring to learners' experience related to the word or using gestures. In the literature, researchers have utilized various techniques to make participants perform semantic elaboration including definition and example matching (Coomber, Ramstad, \& Sheets, 1986), making a sentence using the target word (Barcroft, 2000), giving a rating to the target word on a scale of pleasantness (Barcroft, 2002), answering a question about the word (Barcroft, 2003), and using varied visual representation of referents for target vocabulary (Sommers \& Barcroft, 2013). In the present study, semantic elaboration is operationalized through teacher-performed gestures. A very common technique among language instructors to draw learners' attention to the meaning of a new word is using gestures. Besides, the present study is a case of Persian speakers learning English. Since Persian and English utilize different orthography, results of the study may provide new venues for further investigation of effects of using semantic elaboration in EFL learning and teaching for learners 
Using gestures and English as a Foreign Language vocabulary learning: Does gender make a difference?

whose languages use different orthographies from English.

\subsection{Research questions}

This study aims to address the following questions:

$>\quad$ Does the using of gestures in teaching EFL affect the free recall of new words in English for males and females differently? What is the nature of this relationship for both genders?

$>\quad$ Does the using gestures in teaching affect free recall of new words in native tongue (here Persian) for males and females differently? What is the nature of this relationship for both genders?

Dependent variables are free recall in English and free recall in Persian. Independent variables or conditions of the experiments include using gestures along with new words as experimental condition and not using gestures along with new words as control condition for males and females separately.

\section{Literature review}

In regard to the effects of semantic and structural elaboration on lexical learning there are at least three important theories in the related literature, namely Levels Of Processing model (LOP), Transfer Appropriate Processing model (TAP), and Type Of Processing-Resource Allocation model (TOPRA) which are discussed here.

One of the well-documented theories related to the memory in the framework of cognitive psychology is "Levels of Processing" (LOP) theory which was proposed by Craik and Lockhart (1972). In their seminal work they questioned the adequacy of previous multi-store models of human memory which were dominated by the concept of stores and information transfers among the stores. They argued that multi-store formulation is unsatisfactory in terms of its capacity, coding, and forgetting characteristics. They introduced the conception of "Depth of Processing" which claims that the perception involves the analysis and processing of stimuli at a number of levels. The beginning stages of perception involves the analysis of sensory features (e.g. loudness, pitch, angles lines, etc.) while later stages include pattern recognition and the extraction of meaning (Craik \& Lockhart, 1972). Generally, deep processing indicates greater amount of semantic analysis. This hierarchy of processing levels of analysis for perception was adopted in other theories as well (e.g. Sutherland, 1968; Treisman, 1964). Craik and Lockhart (1972) were specifically concerned with memory trace as a result of perceptual analysis. They argue that the durability of a trace is interrelated to the depth of processing in a way that the deeper levels of analysis make more elaborate, longer lasting, and stronger traces. Based on the levels of processing (LOP) framework, semantic processing is beneficial for retention (Craik \& Lockhart, 1972; Craik \& Tulving, 1975). Some studies have demonstrated that mature participants instructed to perform a semantic processing task on a list of words demonstrated better retention than participants instructed to perform a non-semantic processing task (e.g., MacDaniel \& Masson, 1977). There has been a number of studies supporting the levels of processing (e.g. Atkinson \& Raugh, 1975; Bower \& Reitman, 1972; Craik \& Tulving, 1975; Ellis \& Beaton, 1995; Epstein, Philips, \& Johnson, 1975; Hyde \& Jenkins, 1969; Till \& Jenkins1973; and Walsh \& Jenkins, 1973 among others).

Craik's Levels of semantic processing (1972) has been subject to adjustments in the following years (Fisher \& Craik 1977; Jacoby \& Craik1978). In the adjusted versions, for instance, it was suggested that there is no difference in the durability of traces made by semantic versus non-semantic (e.g. orthographic and phonological) processing but traces that are made by deeper levels of processing are more distinguishable than those made by shallower levels of processing (see Jacoby \& Craik, 1978). However the idea of "levels of processing" never changed in the LOP framework. A criticism for LOP framework is that it does not explicitly mention why semantic processing is deep, meaningful, and permanent and structural processing is shallow non meaningful and less permanent compared to semantic processing. In other words just semantic related processing seems to 
Ghasemi, E., \& Feyzi Behnagh, R.

be meaningful in LOP. As Moeser (1983) claims "The notion of qualitative differences among levels has never been precisely explained or illustrated by proponents of the levels model” (p. 316). There is a group of studies which have suggested the consideration of some other memory factors such as trace uniqueness, trace congruity, etc. (e.g. Craik \& Tulving 1975; Moscovitch \& Craik, 1976). Some other researchers have mentioned the need of differentiating levels of processing in the semantic level of analysis in the mind (e. g. Schulman, 1974).

Morris, Bransford and Franks (1977) manipulated LOP as a function of acquisition task and the type of recognition test in three experiments. Based on their results they argued that there is a need for reconsideration of certain assumptions underlying the levels of processing approach. In particular, they questioned arguments that non-semantic or shallow levels of processing are necessarily inferior to deeper levels of processing. They claim that the reason for this so-called inferiority may be due to the inappropriateness of relationship between acquisition task and test type rather than inherent inferiority of the memory traces resulted from shallow levels of processing in conducted studies. They suggested a new framework named "Transfer Appropriate Processing" (or TAP) as a replacement for LOP. This new framework emphasizes that a) the value of particular acquisition activities must be defined relative to particular goals and purposes, and b) assumptions about the quality and durability of the resulting memory traces can be determined relative to the appropriateness of testing situation. In other words, TAP claims that one should not assume that the traces of certain items are less durable or efficient than others because those items were processed at shallower levels. Transfer Appropriate Processing does not assumes any inherent difference in the nature of memory traces resulting from semantic versus non-semantic levels of processing. There are some related studies supporting TAP model (e.g. MacDaniel \& Kearney, 1984; Moeser, 1983).

A related framework with emphasis on the type of the test relative to the type of task regarding the effectiveness of a given encoding activity is Task-appropriate processing suggested by MacDaniel and Kearney (1984). They claim that their approach, compared to TAP model, is broader and better in capturing the variability in the effectiveness of different types of processing (encoding strategies). They assume that any aspect of a given learning task has an impact (or impacts) on the effectiveness of applied encoding processes aimed at enhancing retention. These aspects include both the task and materials to be learned (p. 371).

In the same line of research on semantic and structural processing, Barcroft (2000) proposed TOPRA model which is consistent with TAP model. This model focuses on competition for limited cognitive resources when learners try to learn different things at the same time. It predicts that when demands of processing are sufficiently high, semantic elaboration can increase learning rates for the semantic properties of words while decreasing learning rates for the structural properties of words at the same time. This model also claims that structural elaboration can simultaneously increase learning rates for structural properties of new words while decreasing learning rates for the semantic properties of words. The model confirms that with restricted processing resources that learners have, it is difficult to process input for both meaning and form. He conducted some other studies to provide more support for his model (e.g. Barcroft, 2003, 2004, 2006, \& 2007).

\subsection{Gestures and memory}

There are several studies investigating the effects of using gestures on memory which have tried to investigate different aspects of this relationship including memory enhancement, accessibility of words and phrases, facilitated recall, reaction time, word frequency in language use, learning of words and action phrases, and retention. A seminal laboratory study dealing with effects of performing gestures on verbal memory dates back to 1980s. Engelkamp and Krumnacker (1980) in Germany found that if verbal phrases for actions are encoded by self-performed representational actions, their retrieval is better than if the verbal information is only heard or read. Independently, Ronald Cohen (1981) conducted a similar study and his findings were highly consistent with the work of Engelkamp and Krumnacker (1980). This effect is called Enactment Effect, Self-Performed Task (SPT) effect, or Action Memory in the related literature. In the same line of investigation, Zimmer, Helstrup, and Engelkamp (2000) investigated the effect of enactment on accessibility in memory. They 
Using gestures and English as a Foreign Language vocabulary learning: Does gender make a difference?

concluded that enacted verbal materials have a better accessibility in memory, and free recall for enacted items happens with less effort.

Spranger, Schatz, and Knopf (2008) in a study of accessibility of enacted items in younger and older adults found high accessibly for both age groups in immediate and delayed free recall tasks. Masumoto, Yamaguchi, Sutani, and others (2006), noted the use of magneto-encephalography to find reasons for memory enhancement effect of enactment, observed that enacted phrases had a higher speed of recognition compared to phrases encoded only audio-visually. In a more recent study, Macedonia and Knosch (2011) conducted a research on the effects of using gesture on abstract word learning. They also investigated if learning new words with self-performed gestures facilitates sentence production. They concluded that self-performed gestures produce better memory for abstract words than the condition of encoding words only audio-visually. They also observed more frequency for words presented with gestures in sentence production by participants.

Macedonia and Kriegstein (2012) claim that "the first study on the impact of gestures on memory for verbal information in a foreign language was conducted by Quinn-Allen (1995)". In a study of learning French expressions (as a foreign language) Quinn-Allen (1995) found that learning emblematic gestures with simultaneously presented expressions does lead to greater recall and more retention over time. In another study of the effects of gestures on foreign language learning, Tellier (2008) examined French children that learned EFL (English as a Foreign Language). She asserts that using gestures in presentation of L2 lexical items and specially their reproductions by learners significantly influence the memorization of them as far as active knowledge of vocabulary is concerned. There has been other studies on other aspects of effects of gestures on memory for foreign language words and expressions too (for example Khalili, Rhmany, \& Zarei, 2014 among others who studied resolving lexical ambiguity by gestures), all of which confirmed the positive effects of utilizing gestures for foreign language teaching and learning (see Macedonia \& Kriegstein, 2012 for a review).

Findings from above-mentioned studies among other similar memory-related ones show the enhancing effects of using gestures on verbal memory. However, in almost all of above-mentioned studies in the experimental conditions, participants were required to learn and perform gestures themselves by providing some form of modeling. In regular foreign or second language classes this approach does not seem plausible; it needs special teacher training, syllabus design, and supervision and it may not be applicable to all language learners (for example adults may be reluctant to use gestures to communicate in classes because they may feel insecure in terms of their egos) and all contexts (Scovel, 1978). In regular second language classes, teacher may use gestures to communicate or focus on the message and students are usually not asked to learn and replicate the gestures although they may learn them indirectly and use them unconsciously. The present paper tries to study the condition of regular adult EFL classes in which only teachers use gestures along with audiovisual presentation of items not students.

\section{Methodology}

\subsection{Participants}

This study was conducted in Iran. From junior and senior undergraduate accounting students at Islamic Azad University, Hajiabad branch 60 students (30 male and 30 female) students were randomly selected $(M$ age $=20.4$ years, age range: 18-29 years). The random selection was to partly ensure that the participants represent the larger population of Persian speaking EFL university students. By filling in the consent forms, they agreed to take part in the experiments. They had passed two English courses (Prerequisite English and General courses) at the university before the experiments and none of them had English training beyond the English courses that they had passed at the junior high school and the high school. They were randomly divided into two equal groups (30 members with 15 males and 15 females in each group). 


\subsection{Design}

The study was quasi-experimental in nature. We compared two genders and two vocabulary learning conditions: a. learning with semantic elaboration (+gesture), and b. learning without semantic elaboration (-gesture). In +gesture condition participants were asked to learn words by paying attention to the word-translation pairs along with a video showing the meaning of each word with gestures. In -gesture condition (control condition) participants were asked to do their best to learn each word after watching the word-translation pairs alone.

\subsection{Experimental Words}

Twenty concrete words that could easily be presented and understood through pictures were selected and divided into two equal groups based on the number of syllables in each word. In order to study words of different length, one-syllable, two-syllable, and three-syllable words were included. To keep a balance between two groups in terms of memory load and processing requirements, in each group there were two one-syllable words, five two-syllable words, and three three-syllable words. Each participant was exposed to both conditions but there were two presentation orders (counterbalancing) for the two groups of participants in order to control the possible bias that could result from the order in which the conditions were provided. Participants of the first section tried to learn words 1-10 in +Semantic Elaboration condition and words 11-20 in -Semantic Elaboration condition. Subsequently, the second group was instructed to learn words 1-10 in -Semantic Elaboration condition and words 11-20 in +Semantic Elaboration condition (Table 1).

\section{Table 1}

The conditions and word arrangements for each section

\begin{tabular}{lll}
\hline & First section & Second section \\
\hline Words 1-10 & + S. Elaboration & - S. Elaboration \\
Words $11-20$ & - S. Elaboration & + S. Elaboration \\
\hline
\end{tabular}

\subsection{Instruments}

The following instruments were used to conduct the study:

$>\quad$ A language background questionnaire was used to ensure that all the participants were learning English as a foreign language and they did not use it outside English classes and to ensure that none of them had the experience of learning another foreign or second language.

$>\quad$ A consent form for participation in the study was attached to the questionnaire;

$>\quad$ A test of participants' familiarity with experimental words was used in which they were required to translate 20 English words into Farsi; it was labeled "The pretest" (Appendix A);

$>\quad$ Two sheets of paper that were labeled Post-tests 1 and 2 were prepared for free recall task in English and free recall task in Persian;

$>$ A computer program (a power point file) was designed to present the instructions, experimental words and pictures, and gesture videos related to each target word.

$>$ A Computer and a video projector were used to present the presentation and the testing phases of the study in a timely manner.

\subsection{Procedure}

The following six steps were taken in the process of data gathering: First, participants were asked to fill in 
the consent form and the language background questionnaire. Then they were asked to turn in the papers. Second, in the test of participants' familiarity with experimental words, participants were asked to translate the experimental words in to Farsi. In order to give all the words equal processing time, words were read one by one for the participants by the experimenter with fifteen-second intervals.

Third, participants were instructed about studying phase of the experiment. Instructions were both presented orally and appeared on the screen. They read the following instructions (translated into Farsi): "Two sets of word-translation pairs will be presented to you on the screen. Each set consists of ten pairs. For each set, pay close attention to what you should do. Each set will be presented twice and between each word-translation pair you have eight seconds to do what you are instructed to". There was no time limit at this stage and participants were free to ask any questions if there was any ambiguity. They were required not to take notes during the study phase.

Fourth, immediately after the third stage, the words were presented. In +semantic elaboration condition the following instruction was presented and read: "Ten word-translation pairs will be presented to you followed by a video showing the meaning of them through gestures. Please do your best to learn each word". In -semantic condition (control condition), the following instruction appeared on the screen and was read to the participants: "Ten word-translation pairs will be presented to you. Please do your best to learn the words". As mentioned earlier, each set of words were presented twice. In +semantic elaboration condition the eight-second time between words started after the gesture presentation was finished. Between two presentations of each set there was a one-minute lapse.

The fifth stage was the free-recall task in English. Immediately after the fourth stage, two blank sheets of paper (no.1 and no.2) were distributed and participants were instructed as follows: "Please try to remember and write as many words as you can in English based on what you just saw on screen. Please feel free to write as much of the words as you can and if you are not sure about the spelling do not worry, just write what you can remember". The participants were given six minutes to recall experimental words in English.

Finally, immediately after the free recall task in English, the participants were instructed to remember and write as many words as they could in Persian (free recall in Persian) based on what they saw in the presentation phase. They were given six minutes to complete the task. After the completion of both tasks, the participants were asked to turn in their recall papers.

\section{Results}

None of the participants were able to translate the experimental words in the pretest, which meant the words were new for them. The Lexical Production Scoring Protocol (LPSP, Barcroft, 2000), was used to score free recalls in English. The scoring in LPSP depends of the percentage of letters correct or present that are produced by the participants. For example the score of .25 is given if only one letter is correct (present and at the right place) or if at least $25 \%$ but less than $50 \%$ of the letters are present. This protocol was used to consider partial knowledge of the English words along with the complete knowledge. Each fully remembered word in Persian received 1 point. Then totals were calculated for both free recall tasks in Persian and English in both conditions for each participants. In other words, based on the situation in which the remembered words had been presented, the scores were totaled. Therefore, each participant had two scores for each recall task (+semantic elaboration and -semantic elaboration).

The SPSS software was utilized for the purpose of data analysis. First, a two way repeated-measures ANOVA was used for males and females separately in which the presence or absence of gestures in the presentation phase and the type of recall task were regarded as independent variables and the scores on recall tasks constituted the dependent variables. Descriptive statistics of both genders are presented in Table 2 and Table 3 respectively. 
Ghasemi, E., \& Feyzi Behnagh, R.

Table 2

Descriptive statistics for males

\begin{tabular}{lccc}
\hline & Mean score & SD & Number \\
\hline Free Recall in English, + Elaboration & 1.78 & 1.58 & 30 \\
Free Recall in Persian, + Elaboration & 6.72 & 1.66 & 30 \\
Free Recall in English, - Elaboration & 3.28 & 2.11 & 30 \\
Free Recall in Persian, - Elaboration & 3.52 & 2.43 & 30 \\
\hline
\end{tabular}

Table 3

Descriptive statistics for females

\begin{tabular}{lccc}
\hline & Mean score & SD & Number \\
\hline Free Recall in English, + Elaboration & 2.42 & 1.91 & 30 \\
Free Recall in Persian, + Elaboration & 6.79 & 2.04 & 30 \\
Free Recall in English, - Elaboration & 3.52 & 1.92 & 30 \\
Free Recall in Persian, - Elaboration & 4.69 & 2.01 & 30 \\
\hline
\end{tabular}

The results of repeated-measures ANOVA for males indicated that there was a significant main effect of the type of free recall task $(F(1,29)=77.886, p<.0005)$. In other words disregarding all other variables, the type of recall task had some effect on the scores of recall tasks. A significant main effect of the presence or absence of semantic elaboration following vocabulary presentation was observed too $(F(1,29)=9.414, p$. $=005)$ which meant the scores of recall task were different for +semantic and -semantic conditions. Moreover, there was a significant interaction between the type of recall task and the presence or absence of semantic elaboration in the presentation phase $(F(1,29)=46.556, p=.005)$. Tables 4,5 , and 6 represent the estimated marginal means of above-mentioned main effects for males.

Table 4

Estimated marginal means of the presence (1) or absence (2) of semantic elaboration for males

\begin{tabular}{ccc}
\hline Elaboration & Mean & Standard error \\
\hline 1 & 4.25 & .229 \\
2 & 3.40 & .325 \\
\hline
\end{tabular}

Table 5

Estimated marginal means of Free Recall tasks in English and Persian for males

\begin{tabular}{lcc}
\hline \multicolumn{1}{c}{ Free Recall } & Mean & Standard error \\
\hline In English & 2.53 & .271 \\
In Persian & 5.18 & .299 \\
\hline
\end{tabular}

Table 6

Estimated marginal means of Semantic Elaboration* Free Recall Task for males

\begin{tabular}{cccc}
\hline Condition & Recall task & Mean & Standard error \\
\hline+ Semantic Elaboration & Free Recall in English & 1.78 & .288 \\
& Free Recall in Persian & 6.72 & .233 \\
- Semantic Elaboration & Free Recall in English & 3.28 & .386 \\
& Free Recall in Persian & 3.52 & .444 \\
\hline
\end{tabular}

The results of repeated-measures ANOVA for females showed that there was a significant main effect of the presence or absence of the type of free recall task too $(F(1,29)=5.771, p<.05)$. Moreover, a significant main effect of the presence or absence of semantic elaboration following vocabulary presentation was observed $(F(1$, $29)=155.419, p .<0005)$ which meant the scores of recall task were different for +semantic and -semantic conditions. Besides, there was a significant interaction between the type of recall task and the presence or absence of semantic elaboration in the presentation $(F(1,29)=34.192, p<.0005)$. Tables 7,8 , and 9 represent the estimated marginal means of above-mentioned main effects for females. 
Using gestures and English as a Foreign Language vocabulary learning: Does gender make a difference?

Table 7

Estimated marginal means of the presence (1) or absence (2) of semantic elaboration for females

\begin{tabular}{ccc}
\hline Elaboration & Mean & Standard error \\
\hline 1 & 4.60 & .316 \\
2 & 4.10 & .312 \\
\hline
\end{tabular}

Table 8

Estimated marginal means of Free Recall tasks in English and Persian for females

\begin{tabular}{lcc}
\hline \multicolumn{1}{c}{ Free Recall } & Mean & Standard error \\
\hline In English & 2.97 & .311 \\
In Persian & 5.74 & .321 \\
\hline
\end{tabular}

Table 9

Estimated marginal means of Semantic Elaboration* Free Recall Task for females

\begin{tabular}{cccc}
\hline Condition & Recall task & Mean & Standard error \\
\hline + Semantic Elaboration & Free Recall in English & 2.42 & .349 \\
& Free Recall in Persian & 6.79 & .373 \\
- Semantic Elaboration & Free Recall in English & 3.52 & .350 \\
& Free Recall in Persian & 4.69 & .366 \\
\hline
\end{tabular}

Pairwise comparison for both males and females showed statistically significant differences between mean scores of free recall in English and free recall in Persian but not for the presence or absence of semantic elaboration (at the .05 level).

In order to compare effects of the two conditions (presence and absence of semantic elaboration) on the scores of two recall tasks, one way repeated-measures ANOVA was utilized for each gender group separately. In other words, the mean scores of +semantic elaboration and -semantic elaboration conditions of each recall task were compared using one way repeated-measures ANOVA.

The results of analysis for males showed a statistically significant difference between the means of +semantic elaboration and -semantic elaboration conditions of free recall in English, (free recall in -semantic elaboration condition was higher), and free recall in Persian, (free recall in +semantic elaboration condition was higher). (See Table 10)

\section{Table 10}

Comparison of +semantic and-semantic elaboration conditions in recall tasks for males

\begin{tabular}{cccc}
\hline Recall Task & Recall Task & Mean & Sig. \\
\cline { 2 - 4 }+ Semantic Condition & -Semantic condition & \multicolumn{2}{c}{ Difference } \\
\hline Free Recall in English & Free Recall in English & -1.50 & .006 \\
Free Recall in Persian & Free Recall in Persian & 3.20 & .000 \\
\hline
\end{tabular}

The same analysis for females group showed the same results (i.e. a statistically significant difference between two conditions). The related figures are presented in Table 11.

\section{Table 11}

Comparison of +semantic and-semantic elaboration conditions in recall tasks for females

\begin{tabular}{cccc}
\hline Recall Task & Recall Task & Mean & Sig. \\
\cline { 2 - 4 } +Semantic Condition & -Semantic condition & \multicolumn{2}{c}{ Difference } \\
\hline Free Recall in English & Free Recall in English & -1.10 & .000 \\
Free Recall in Persian & Free Recall in Persian & 2.10 & .000 \\
\hline
\end{tabular}

In sum, the results show that the use of semantic elaboration could have statistically significant effects on 
Ghasemi, E., \& Feyzi Behnagh, R.

free recall in English (research question 1) and free recall in Persian (research question 2) for both genders. However, the nature of these effects is not the same. Using semantic elaboration through gestures negatively affected the scores of free recall in English as a foreign language. In contrast, using gestures positively affected the scores of free recall in Persian as the native tongue.

\section{Discussion and pedagogical implications}

Ghasemi and Feyzi Behnagh (2016) conducted a similar study with adults without gender division and came to similar results. In comparison of L1 and L2, it seems, semantic elaboration facilitates free recall in the first language more than second language for both genders. Following, the present findings are evaluated in the frameworks of LOP, TAP, and TOPRA models.

The findings are consistent with LOP model (Craik \& Lockhart, 1972) as long as we only consider the participants' first language. It seems semantic elaboration increased the depth of word processing which consequently increased the free recall of words in the native tongue. However, this is not the case for a foreign language. The results show that semantic elaboration negatively affected free recall in English (as a foreign language).

The present findings provide partial support for TOPRA model (Barcroft, 2000) too. Comparing mean scores of free recall tasks in English in the presence of semantic elaboration was significantly lower than the control condition. Maybe, paying attention to gestures distracted the participants and used the processing resources that could otherwise be utilized for learning new words. The results show the opposite for free recall tasks in Persian.

In addition, the study partly supports TAP model (Morris et al., 1977). In the presentation phase of the study (encoding), participants were required to direct their attention to videos (gestures). Maybe, this task had no relation to the testing phase in which they were asked to write as many words as they could remember from the presentation phase. It may be argued that the participants could have got higher scores in free recall tasks in English (which focused on structural properties of words) if in presentation phase they were required to pay attention to structural properties of words, for example by asking them to count the number of consonants and vowels of each word (Morris et al., 1977). In the case of free recall tasks in Persian, since participants already knew the words in their native tongue, there was no need to encode it in mind in the first place (Barcroft, 2004); the semantic elaboration (gestures) had a facilitative role since it helped them process experimental words more easily.

Moreover, the positive effect of semantic elaboration on memory for known words in participants' native language is consistent with several previous studies which found that semantic elaboration positively affects memory for known words (e.g. Bower \& Reitman, 1972; Hyde \& Jenkins, 1969; Ross, 1981; Schulman, 1974; Tresselt \& Mayzner, 1960). Barcroft (2000) found that free recall in English (known language) was grater in the semantic elaboration condition (operationalized through making pleasantness rating about word referents) compared to structural elaboration condition. However, McDaniel and Kearney (1984) found that semantic orienting conditions resulted in less vocabulary recall than uninstructed condition for a known language. Barcroft (2007) found that word writing (forced output) inhibited word learning by exhausting limited processing resources available for word learning which is consistent with the findings of present study regarding free recall in English (foreign language). The findings also support Sommers and Barcroft (2013) who found that semantic elaboration (operationalized through token variability in presentation phase) produced negative effects on L2 vocabulary learning in contrast to previous studies which found positive effects of word form variability (emphasizing on structural properties of words) on L2 vocabulary learning.

In a study on Iranian EFL learners, Khalili, Rahmani, and Zarei (2014) found a positive effect for using gestures on resolving English lexical ambiguity; however, the gestures were both teacher and student performed which may not provide an appropriate basis for comparison. In another study, Ahmadi (2014) found no 
significant positive significant effect for elaboration on retention of EFL vocabulary compared to the control condition (structural elaboration).

Followings are some implications for teaching foreign languages are provided: First, based on the results of the free recall tasks in the present study (and TOPRA model), language learners have limited information processing resources. Therefore, teachers should recognize this limitation and consider it when they teach. They should not expect students to process several pieces of new information simultaneously. Moreover, language teachers should recognize a distinction between semantic and structural properties of words when they are focusing on vocabulary, and deal with them separately. In other words, when teachers decide to teach new words, they should draw learners' attention to one aspect of words at a time. For example, they may first emphasize the specific situations in which the word is used, the degree of formality of that word, the synonyms, antonyms, distinctive semantic properties of the word in the target language compared to native language, matching the word to its picture, and using gestures to clarify its meaning, all of which refer to semantic properties of the words with different degrees. After that, they may draw learners' attention to structural properties of the word such as pronunciation, pitch and stress patterns, number of syllables, and arrangement of vowels and consonants. They may change the order but it does not seem appropriate to use a combination of these two stages.

Testing and measurement is another related issue. There should be a match between the presented materials and the way they are presented and what the test (e.g. quizzes, midterm and final examinations) measures. In other words, if the presentation of materials puts emphasis on semantic properties of new words, the test should not ask about formal characteristics. For example, asking students to write the definition of a new word is a semantically-oriented task which should be used if in teaching the emphasis has been on the meaning of the target word. In contrast, asking learners to write the target word in the exam is basically structurally oriented.

We believe book compilers should consider the same notion of match between encoding and testing tasks in writing EFL and ESL vocabulary learning textbooks, more specifically in the compilation of exercises related to each unit. Exercises should be tuned to the way the materials are presented.

In addition, foreign and second language teachers seem to be biased in using semantic elaboration techniques. As Sommers and Barcroft (2013) claim in spite of mounting body of evidence showing that semantically-oriented tasks do not facilitate L2 word form (i.e. structure) learning, many L2 instructors and other language learning professional do not consider this basic pedagogical guideline to be intuitive. Therefore there should be a reconsideration of this standpoint.

Finally, noting the distinction between the role of teacher-and-student-used gestures and teacher-only-used gestures seems to be important for future studies. In related literature, there are numerous studies supporting the positive role of the former in learning both first language and second language; however the findings of the present study shows, that at least with regards to formal properties of L2 words (manifested in free recall tasks), the effect of the latter may not be necessarily positive.

Acknowledgements: This study has been sponsored by Islamic Azad University, Hajiabad Branch.

\section{References}

Ahmadi, M. (2014). Semantic and structural elaboration in L2 vocabulary learning and retention. ProcediaSocial and Behavioral Sciences, 98, 109-115. https://doi.org/10.1016/j.sbspro.2014.03.395

Atkinson, R. C., \& Raugh, M. R. (1975). An application of the mnemonic keyword method to the acquisition of a Russian vocabulary. Journal of Experimental Psychology: Human Learning and Memory, 104, 126-133. https://doi.org/10.1037/0278-7393.1.2.126

Ausubel, D. P. (1964). Adults versus children in second-language learning: Psychological considerations. Modern Language Journal, 48, 420-424. https://doi.org/10.1111/j.1540-4781.1964.tb04523.x 
Ghasemi, E., \& Feyzi Behnagh, R.

Barcroft, J. (2000). The effects of sentence writing as semantic elaboration on allocation of processing resources and second language acquisition (Unpublished doctoral dissertation). University of Illinois at Urbana-Champaign.

Barcroft, J. (2002). Semantic and structural elaboration in L2 lexical acquisition. Language Learning, 52, 323-363. https://doi.org/10.1111/0023-8333.00186

Barcroft, J. (2004). Effects of sentence writing in L2 lexical acquisition. Second Language Research, 20(4), 303-334. https://doi.org/10.1191/0267658304sr233oa

Barcroft, J. (2006). Can writing a new word detract from learning it? More negative effects of forced output during vocabulary learning. Second Language Research, 22(4), 487-497. https://doi.org/10.1191/0267658306sr276oa

Barcroft, J. (2007). Effects of opportunities for word retrieval during second language vocabulary learning. Language Learning, 57(1), 35-56. https://doi.org/10.1111/j.1467-9922.2007.00398.x

Batia, L., \& Jan, H. (2001). Incidental vocabulary acquisition in a second language: The construct of task-induced involvement. Applied Linguistics, 22, 1-26. https://doi.org/10.1093/applin/22.1.1

Bower, G. H., \& Reitman, J. S. (1972). Mnemonic elaboration in multi-list learning. Journal of Verbal Learning and Verbal Behavior, 11, 478-485. https://doi.org/10.1016/S0022-5371(72)80030-6

Brown, T. S. \& Perry, L. P. (1991). A comparison of three learning strategies for ESL vocabulary acquisition. TESOL Quarterly, 25(4), 655-670. https://doi.org/10.2307/3587081

Cohen, R. L. (1981). On the generality of some memory laws. Scandinavian Journal of Psychology, 22, $267-281$. https://doi.org/10.1111/j.1467-9450.1981.tb00402.x

Coomber, J. E., Ramstad, D. A., \& Sheets, D. R. (1986). Elaboration in vocabulary learning: A comparison of three rehearsal methods. Research in the teaching of English, 20, 281-293

Craik, F. I. M., \& Lockhart, R. S. (1972). Levels of processing: A framework for memory research. Journal of Verbal Learning and Verbal Behavior, 11, 671-684. https://doi.org/10.1016/S0022-5371(72)80001-X

Craik, F. I. M., \& Tulving, E. (1975). Depth of processing and the retention of words in episodic memory research, Journal of Experimental Psychology: General, 104, 268-294. https://doi.org/10.1037/0096-3445.104.3.268

Crow, J. T., \& Quigly, J. R. (1985). A semantic field approach to passive vocabulary acquisition for reading comprehension. TESOL Quarterly, 19(3), 479-513. https://doi.org/10.2307/3586275

Dulay, H. C., \& Burt, M. K. (1974). Natural sequences in child second language acquisition. Language Learning, 24(1), 37-53. https://doi.org/10.1111/j.1467-1770.1974.tb00234.x

Ellis, N., \& Beaton, A. (1995). Psychologistic determinants of foreign language vocabulary learning. In B. Hardy (Ed.), Lexical issues in language learning (pp. 107-165). Ann Arbor, MI: Benjamins.

Engelkamp, J., \& Krumnacker, H. (1980). Imaginale und motorische prozesse beim behalten verbalem materials [Imaginary and motor processes during retention of verbal material]. Journal of Experimental and Applied Psychology, 27, 511-533.

Epstein, M. L., Philips, W. D., \& Johnson, S. J. (1975). Recall of related and unrelated word pairs as function of processing level. Journal of Experimental Psychology: Human Learning and Memory, 104, 149-152. https://doi.org/10.1037/0278-7393.1.2.149

Fisher, R. P., \& Craik, F. I. M. (1977). Interaction between encoding and retrieval operations in cued recall. Journal of Experimental Psychology: Human Learning and Memory, 3, 701-711. https://doi.org/10.1037/0278-7393.3.6.701

Folse, K. S. (2006). The effect of type of written exercise on L2 vocabulary retention. TESOL Quarterly, 40, 273-293. https://doi.org/10.2307/40264523

Fraser, C. A. (1999). Lexical processing strategy use and vocabulary learning through reading. Studies in Second Language Acquisition, 21, 225-241. https://doi.org/10.1017/s0272263199002041

Ghasemi, E., \& Feyzi Behnagh, R. (2016). A study of the effects of teacher-performed gestures as a means of semantic elaboration on L2 word learning and retention. International Journal of Research Studies in Language Learning, 6(3), 47-61.

Giacobbe, J. (1992). A cognitive view of the role of L1 in the L2 acquisition process. Second Language Research, 
Using gestures and English as a Foreign Language vocabulary learning: Does gender make a difference?

8, 232-250https://doi.org/10.1177/026765839200800304

Goldschneider, J., \& DeKeyser, R. M. (2001). Explaining the "natural order of L2 morpheme acquisition" in English: A meta-analysis of multiple determinants. Language Learning, 51(1), 1-50. https://doi.org/10.1111/1467-9922.00147

Hyde, T. S., \& Jenkins, J. J. (1969). The differential effects of incidental tasks on the organization of recall of a list of highly associated words. Journal of Experimental Psychology, 82, 472-481. https://doi.org/10.1037/h0028372

Jacoby, L. L., \& Craik, F. I. M. (1979). Effects of elaboration of processing at encoding and retrieval: Trace distinctiveness and recovery of initial context. In L. S. Cermak \& F. I. M. Craik (Eds.), Levels of processing in human memory (pp. 1-21). Hillsdale, NJ: Lawrence Erlbaum Associates.

Jiang, N. (2002). Form-meaning mapping in vocabulary acquisition in a second language. Studies in Second Language Acquisition, 24, 617-637. https://doi.org/10.1017/s0272263102004047

Khalili, M., Rahmany, R., \& Zarei, A. A. (2014). The effects of using gestures on resolving lexical ambiguity in L2. Journal of language Teaching and Research, 5(5), 1139-1146. https://doi.org/10.4304/jltr.5.5.1139-1146

Laufer, B., \& Paribakht, T. S. (1998). The relationship between passive and active vocabularies: Effects of language learning context. Language Learning, 48(3), 365-391. https://doi.org/10.1111/0023-8333.00046

Levelt, W. J. M. (1989). Speaking: From intention to articulation. Cambridge, MA: MIT Press.

Macedonia, M., \& Knosch, T. R. (2011). Body in mind: How gestures empower foreign language learning. Mind, Brain, and Education, 5(4), 196-211. https://doi.org/10.1111/j.1751-228X.2011.01129.x

Macedonia, M., \& Kriegstein, K. V. (2012). Gestures enhance foreign language learning. Biolinguistics, 6(3-4), 303-416.

Masumoto, K., Yamaguchi, M., Sutani, K., Tsuneto, S., Fujita, A., \& Tonoike, M. (2006). Reactivation of physical motor information in the memory of action events. Brain Research, 1101(1), 102-109. https://doi.org/10.1016/j.brainres.2006.05.033

McDaniel, M. A., \& Kearney, E. M. (1984). Optimal learning strategies and their spontaneous use: The importance of task-appropriate processing. Memory and Cognition, 12(4), 361-373. https://doi.org/10.3758/BF03198296

McDaniel, M. A., \& Masson, M. E. (1977). Long-term retention: When incidental semantic processing fails. Journal of experimental Psychology: Human Learning and Memory, 3, 270-281. https://doi.org/10.1037/0278-7393.3.3.270

Meara, P. (1995). The importance of an early emphasis on L2 vocabulary. The Language Teacher, 19(2), 8-11

Moeser, S. D. (1983). Levels of processing: qualitative differences of task-demand differences? Memory and Cognition, 11, 316-323. https://doi.org/10.3758/BF03196978

Morris, C. D., Bransford, J. D., \& Franks, J. J. (1977). Levels of processing versus transfer appropriate processing. Journal of Verbal Learning and Verbal Behavior, 16, 519-533. https://doi.org/10.1016/S0022-5371(77)80016-9

Moscovitch, M., \& Craik, F. I. M. (1976). Depth of processing, retrieval cues, and uniqueness of encoding as factors in recall. Journal of Verbal Learning and Verbal Behavior, 15, 447-458. https://doi.org/10.1016/S0022-5371(76)90040-2

Oxford, R. (1990). Language Learning Strategies: What every teacher should know. Rowley, MA: Newbury House.

Quinn-Allen, L. (1995). The effects of emblematic gestures on the development and access of mental representation of French expressions. The Modern Language Journal, 79(4), 521-529. https://doi.org/10.1111/j.1540-4781.1995.tb05454.x

Ringbom, H. (1983). Borrowing and lexical transfer. Applied Linguistics, 4, 207-212. https://doi.org/10.1093/applin/4.3.207

Ross, B. H. (1981). The more, the better? Number of decisions as a determinant of memorability. Memory and Cognition, 9, 23-33. https://doi.org/10.3758/BF03196948 
Ghasemi, E., \& Feyzi Behnagh, R.

Schmitt, N. (2000). Vocabulary in language teaching. Cambridge: Cambridge University Press.

Schulman, A. (1974). Memory for words recently classified. Memory and Cognition, 2, 47-52. https://doi.org/10.3758/BF03197491

Scovel, T. (1978). The effect of affect on foreign language learning: A review of anxiety research. Language learning, 28(1), 129-142. https://doi.org/10.1111/j.1467-1770.1978.tb00309.x

Sommers, M., \& Barcroft, J. (2013). Effects of referent token variability on L2 vocabulary learning. Language Learning, 63(2), 186-210. https://doi.org/10.1111/lang.12007

Spranger, T., Schatz, T. R., \& Knopf, M. (2008). Does action make you faster? A retrieval-based approach to investigating the origins of the enactment effect. Scandinavian Journal of Psychology, 49(6), 487-495. https://doi.org/10.1111/j.1467-9450.2008.00675.x

Sutherland, N. S. (1968). Outlines of a theory of visual pattern recognition in animals and man. Proceedings of the Royal Society. Series B, 171, 297-317. https://doi.org/10.1098/rspb.1968.0072

Tellier, M. (2008). The effect of gestures on second language memorization by young children. Gesture, 8(2), 219-235. https://doi.org/10.1075/gest.8.2.06tel

Till, R. E., \& Jenkins, J.J. (1973). The effects of cued orienting tasks on the free recall of words. Journal of Verbal Learning and Verbal Behavior, 12, 489-498. https://doi.org/10.1016/S0022-5371(73)80029-5

Treisman, A. (1964). Monitoring and storage or irrelevant messages in selective attention. Journal of Verbal Learning and Verbal Behavior, 3, 449-459. https://doi.org/10.1016/S0022-5371(64)80015-3

Tresselt, M. E., \& Mayzner, M. S. (1960). A study of incidental learning. Journal of Psychology, 50, 339-347. https://doi.org/10.1080/00223980.1960.9916451

Walsh, D. A., \& Jenkins, J. J. (1973) Effects of orienting tasks on free recall in incidental learning: "Difficulty," "effort," and "process" explanations. Journal of Verbal Behavior, 12, 481-488. https://doi.org/10.1016/S0022-5371(73)80028-3

West, M. (1953). A general service list of English words. London: Longman

Zimmer, H. D., Helstrup, T., \& Engelkamp, J. (2000). Pop-out into memory: A retrieval mechanism that is enhanced with the recall of subject-performed tasks. Journal of Experimental Psychology: Learning, Memory, and Cognition, 26(3), 658-670. https://doi.org/10.1037/0278-7393.26.3.658 